\title{
Comparison of Methods for Detection of Escherichia coli 0157:H7 in Ground Beef and Radish Sprouts
}

\author{
Jae-Hoon Lee, Ji-Yeon Hyeon, Seok Heo ${ }^{1}$, In-Gyun Hwang ${ }^{1}$, Hyo-Sun Kwak ${ }^{1}$, \\ In-Soo $\mathrm{Choi}^{2}$, Chankyu Park ${ }^{3}$, and Kun-Ho Seo* \\ Department of Public Health, College of Veterinary Medicine, Konkuk University, Seoul 143-701, Korea \\ ${ }^{1}$ Food Microbilogy Division, National Instituet of Food and Drug Safety Evaluation, \\ Korea Food and Drug Administration, Seoul 122-704, Korea \\ ${ }^{2}$ Department of Infectious Diseases, College of Veterinary Medicine, Konkuk University, Seoul 143-701, Korea \\ ${ }^{3}$ Department of Animal Biotechnology, Konkuk University, Seoul 143-701, Korea
}

\begin{abstract}
Escherichia coli $\mathrm{O} 157: \mathrm{H} 7$ is a food-borne pathogen that causes bloody diarrhea, hemorrhagic colitis, and hemolytic uremic syndrome (HUS). We compared three selective media and evaluated the performance of immunomagnetic separation (IMS) for the detection of low levels of E. coli O157:H7 in ground beef and radish sprouts with different levels of background flora. Bulk food samples (500 g for each trial) were artificially inoculated with nalidixic acid-resistant $E$. coli $\mathrm{O} 157: \mathrm{H} 7$ at the lowest dose that would generate 20 partial-positive samples of $25 \mathrm{~g}$ each. All samples were homogenized in mTSB $(225 \mathrm{~mL})$ and incubated overnight at $37^{\circ} \mathrm{C}$. IMS was performed using the enriched $\mathrm{mTSB}$ samples $(1 \mathrm{~mL})$ along with conventional spreads plated onto three different selective media: Sorbitol MacConkey agar (SMAC), Sorbitol MacConkey agar with cefixime and tellulite (CT-SMAC), and Sorbitol MacConkey agar with nalidixic acid (NAL-SMAC) as the gold standard. Two suspicious colonies from each medium were selected and confirmed using a serological test after transfer to tryptic soy broth with yeast extract (TSAYE). CT-SMAC was better than SMAC for detecting E. coli O157:H7 in all food types. Although there was no statistical difference in the number of positive samples when using IMS vs. non-IMS techniques, more positive samples were detected when IMS was used in both ground beef and radish sprouts. It appears that the improvement was more significant in radish sprouts, which had a higher level of background flora than ground beef. The results also suggest that the combination of CT-SMAC and IMS is sufficient to recover low levels of E. coli O157:H7 in high background flora food samples.
\end{abstract}

Key words: detection, selective media, immunomagnetic separation, Escherichia coli $\mathrm{O} 157: \mathrm{H} 7$

\section{Introduction}

Since the recognition of Escherichia coli $\mathrm{O} 157: \mathrm{H} 7$ as an important food-borne pathogen in the early 1980 s, it has emerged as an important food-borne pathogen (Onoue et al., 1999; Riley et al., 1983). The pathogenicity of E. coli $\mathrm{O} 157: \mathrm{H} 7$ is primarily associated with the Shiga toxin, which causes bloody diarrhea, hemolyticuremic syndrome (HUS) and thrombotic and thrombocytopenic purpura (TTP) in children and adults (Chapman et al., 2001; Fu et al., 2005; Karch et al., 1996). The primary reservoir of E. coli $\mathrm{O} 157: \mathrm{H7}$ is cattle, so most out-

*Corresponding author: Kun-Ho Seo, Department of Public Health, College of Veterinary Medicine, Konkuk University, Seoul 143-701, Korea. Tel: 82-10-9222-4121, Fax: 82-2-4503037, E-mail: bracstu3@konkuk.ac.kr breaks have been associated with the consumption of undercooked ground beef and raw milk. However, fresh produce items such as lettuce, cabbage, alfalfa, spinach, and radish sprouts have been increasingly implicated in recent outbreaks (Ackers et al., 1998; Besser et al., 1993; Onoue et al., 1999; Rangel et al., 2005).

Numerous methods for the detection of E. coli $\mathrm{O} 157: \mathrm{H} 7$ in food have been used in many food inspection laboratories. The standard method of detection of E.coli $\mathrm{O} 157: \mathrm{H} 7$ uses conventional culture techniques, which rely on enrichment of the E. coli $\mathrm{O} 157: \mathrm{H} 7$ in broth medium and plating onto various differential and selective agar media to obtain presumptive colonies, followed by confirmation of isolates using a series of biochemical and serological tests (Deisingh et al., 2004; Fratamico et al., 2007; Jo et al., 2007). Selective and differential media for E. coli $\mathrm{O} 157: \mathrm{H} 7$ have been developed based on the unique characteristics of the 
strain, such as the fact that it does not ferment sorbitol and has moderate resistance against cefixime and potassium tellulite (Fujisawa et al., 2000; Zadik et al., 1993).

However, it has been reported that many bacteria forming colorless colonies similar to $E$. coli $\mathrm{O} 157: \mathrm{H} 7$ on CT-SMAC and present in radish sprouts, causing difficulty in selecting E. coli $\mathrm{O} 157: \mathrm{H} 7$ colonies on this selective medium (Fujisawa et al., 2000). Therefore, many internationally recognized official methods, such as USDA/FSIS and ISO methods, have recommended immunomagnetic separation (IMS) for the detection of $E$. coli $\mathrm{O} 157: \mathrm{H} 7$ in foods.

In recent years, immunomagnetic separation (IMS) methods have become widespread which will result in less false negatives and false positives (Aminul et al., 2006; Deisingh et al., 2004). The method of immunomagnetic separation (IMS) of E. coli O157:H7 from enrichment culture using paramagnetic particles coated with $E$. coli $\mathrm{O} 157$ antibodies has been developed for the selective isolation of this organism from foods contaminated with background flora (Vernozy-Rozand et al., 1998).

Onoue et al. (1999) and Ogden et al. (2001) evaluated various detection methods for the detection of $E$. coli O157:H7 in foods. However, in the previous studies, the inoculums levels were too high and a gold standard procedure was not included resulting in only relative comparison of different methods.

It is important to detect low levels of $E$. coli $\mathrm{O} 157: \mathrm{H} 7$ in foods because the infectious dose of E. coli $\mathrm{O} 157: \mathrm{H} 7$ is estimated to be very low (Ogden et al., 2001). Therefore, the validation of plating media for IMS method in different types of foods inoculated with very low level of $E$. coli $\mathrm{O} 157: \mathrm{H} 7$ is needed. The precise evaluation of the performance of IMS in combination with various selective media has not been completely identified. Moreover, in order to assess the precise efficacy of detection methods, it is important to have a gold standard method for comparison.

The purposes of the present study were to compare three selective agar media (SMAC, CT-SMAC and NALSMAC) and evaluate the efficacy of IMS for the detection of low levels of E. coli $\mathrm{O} 157: \mathrm{H} 7$ in ground beef and radish sprouts, using a nalidixic acid-resistant strain and as the gold standard.

\section{Materials and Methods}

\section{Microorganisms}

Nalidixic acid-resistant E. coli O157:H7 strain \#0025 was obtained from the FDA/CFSAN (5100 Paint Branch
Park way, College Park, Maryland 20740). The stock cultures of nalidixic acid-resistant E. coli $\mathrm{O} 157: \mathrm{H} 7$ were activated by transferring a loopfull of culture onto nutrient agar (Difco, Detroit, USA) at $37^{\circ} \mathrm{C}$ for $24 \mathrm{~h}$. One colony was selected and transferred to tryptic soy broth (TSB: Difco) with $0.5 \%$ yeast extract (TSBYE: Difco), and cultivated at $37^{\circ} \mathrm{C}$ for $24 \mathrm{~h}$. A single colony culture was also streaked onto nutrient agar containing $20 \mu \mathrm{g} / \mathrm{mL}$ nalidixic acid and incubated at $37^{\circ} \mathrm{C}$ for $24 \mathrm{~h}$ to confirm resistance to nalidixic acid.

\section{Sample preparation and inoculation}

The ground beef and radish sprouts were purchased from a retail shop in Seoul, Korea. The nalidixic acidresistant $E$. coli $\mathrm{O} 157: \mathrm{H} 7$ incubated in TSBYE underwent 10 -fold serial dilution with sterilized phosphate buffered saline (PBS, pH 7.4) to the predetermined inoculation concentration. Ground beef and radish sprouts $(500 \mathrm{~g}$ for each sample) were inoculated with nalidixic acid-resistant E. coli $\mathrm{O} 157: \mathrm{H} 7$ at approximately $20 \mathrm{CFU} / 500 \mathrm{~g}$ and $1400 \mathrm{CFU} / 500 \mathrm{~g}$ respectively, and were then divided into 20 samples ( $25 \mathrm{~g}$ per sample) stored in stomacher bags. Negative and positive controls were included. Inoculated samples were stabilized at $4^{\circ} \mathrm{C}$ for $24 \mathrm{~h}$. The number of E.coli $\mathrm{O} 157: \mathrm{H} 7$ inoculates was confirmed by plating on nutrient agar (Difco) and incubated at $37^{\circ} \mathrm{C}$ for $24 \mathrm{~h}$, followed by total colony counting.

\section{Examination of background flora in foods}

Twenty-five grams of ground beef and radish sprouts were mixed with $225 \mathrm{~mL}$ TSB in a stomacher bag. After stomaching, the broth was subjected to 10 -fold serial dilutions to $1: 10^{8}$ with sterile phosphate buffered saline (PBS, pH 7.4). One hundred microliters of the diluted broth were plated onto nutrient agar (Difco) and incubated at $37^{\circ} \mathrm{C}$ for $24 \mathrm{~h}$, followed by total colony counting.

\section{Sample enrichment and direct plating}

To the modified tryptic soy broth (mTSB), autoclaved TSB (30 g/L: Difco) containing bile salt no. 3 (1.5 g/L: Difco) and dipotassium phosphate (1.5 g/L: Difco) was supplemented with novobiocin $(20 \mathrm{mg} / \mathrm{L}$ : Dallynn, Calgary, Canada). All samples (25 g each) were homogenized with $\mathrm{mTSB}(225 \mathrm{~mL} / \mathrm{sample})$ and incubated at $37^{\circ} \mathrm{C}$ for $24 \mathrm{~h}$. After enrichment, broth cultures were streaked onto three selective media: Sorbitol MacConkey agar (SMAC: Difco), Sorbitol MacConkey agar with cefixime and tellulite $(2.5 \mathrm{mg} / \mathrm{L})$ (CT-SMAC: Difco) and Sorbitol MacConkey agar with nalidixic acid $(20 \mathrm{mg} / \mathrm{L})$ 
(NAL-SMAC: Sigma, St. Louis, USA) as the gold standard. All selective media were incubated at $37^{\circ} \mathrm{C}$ for $24 \mathrm{~h}$.

\section{Plating after immunomagnetic separation (IMS)}

E. coli $\mathrm{O} 157: \mathrm{H} 7$ cells in mTSB culture were separated with Dynabeads ${ }^{\circledR}$ anti-E.coli $\mathrm{O} 157$ according to the manufacturer's instructions (Dynal, Oslo, Norway). Briefly, 1 $\mathrm{mL}$ of the mTSB enrichment culture was mixed with 20 $\mu \mathrm{L}$ Dynabeads ${ }^{\circledR}$ anti-E.coli $\mathrm{O} 157$ in an eppendorf tube and incubated at room temperature for $20 \mathrm{~min}$. After being separated from the aliquot with the use of a magnetic particle concentrator (Dynal MPC ${ }^{\circledR}-\mathrm{S}$ : Dynal), the beads were washed with $1 \mathrm{~mL}$ PBS containing $0.05 \%$ Tween 20, separated again and resuspended in $1 \mathrm{~mL}$ PBS-Tween 20. The separation steps were repeated three times. The bead suspension $(20 \mu \mathrm{L})$ was then plated onto SMAC, CT-SMAC and NAL-SMAC and spread over the agar surface with a sterile spreader (Cooley et al., 2007; Ogden et al., 2001).

\section{Serological confirmation test}

Two suspicious colonies from each selective medium were picked up and streaked on tryptic soy agar with $0.6 \%$ yeast extract (TSAYE) and incubated at $37^{\circ} \mathrm{C}$ for 24 h. These colonies were confirmed as E. coli $\mathrm{O} 157: \mathrm{H} 7$ based on the latex agglutination test with Dry spot E. coli O157 (Oxoid Ltd., Basigstoke, UK).

\section{Statistical analysis}

The data were analyzed to determine the significance of the number of positive samples on CT-SMAC and SMAC media compared to the gold standard NAL-SMAC, as well as the significance of the difference in results obtained with immunomagnetic separation (IMS) and direct plating without IMS. All analyses were conducted using the Graphpad InStat statistical program (GraphPad Software Inc., San Diego, CA, USA). P-values < 0.05 indicated statistically significant differences.

\section{Results}

\section{Ground beef}

For the ground beef inoculated with nalidixic acidresistant E.coli $\mathrm{O} 157: \mathrm{H} 7$, three replicates of the experiment were performed to evaluate SMAC and CT-SMAC in combination with IMS compared to the gold standard NAL-SMAC. The average total count of aerobic bacteria in the non-inoculated ground beef used in the triplicate experiment was $2.3 \times 10^{4} \mathrm{CFU} / \mathrm{g}$. The inoculation levels needed to generate partial positives for statistical analysis in each trial were 22,21 , and $18 \mathrm{CFU} / 500 \mathrm{~g}$ of ground beef, respectively. The number and percentage of positive samples out of 20 ground beef samples in each combination of selective media with non-IMS or IMS techniques are shown in Table 1. When compared to NAL-SMAC, CT-SMAC performed better than SMAC in all trials, whether IMS was used or not (Table 1). The mean recovery rate of NAL-SMAC, CT-SMAC, and SMAC in the three trials improved from $50 \%$ to $64 \%(+14 \%), 52 \%$ to $62 \%(+10 \%)$ and $40 \%$ to $52 \%(+12 \%)$, respectively, when IMS was combined with each of the selective media (Table 1). When compared to NAL-SMAC, the recovery rate of CT-SMAC was almost identical to that of the gold standard, while reduced recovery rates, $10 \%$ lower without IMS and 12\% lower with IMS, were observed with SMAC (Table 1).

\section{Radish sprouts}

For radish sprouts, three replicates of the experiment were performed to evaluate CT-SMAC and SMAC in

Table 1. Comparison of selective media and respective number of positive samples with and without IMS in ground beef

\begin{tabular}{|c|c|c|c|c|c|c|c|c|c|c|}
\hline \multicolumn{11}{|c|}{ Number of positive samples/Number of tested samples (\% positive) } \\
\hline Trials & \multicolumn{2}{|c|}{1} & \multicolumn{2}{|c|}{2} & \multicolumn{2}{|c|}{3} & \multicolumn{2}{|c|}{ Total } & \multirow{2}{*}{\multicolumn{2}{|c|}{$p$-value }} \\
\hline \multirow{2}{*}{$\begin{array}{c}\text { Inoculum } \\
(\mathrm{CFU} / 500 \mathrm{~g})\end{array}$} & \multicolumn{2}{|c|}{22} & \multicolumn{2}{|c|}{21} & \multicolumn{2}{|c|}{18} & \multicolumn{2}{|c|}{$20^{\mathrm{a}}$} & & \\
\hline & No IMS & IMS & No IMS & IMS & No IMS & IMS & No IMS & IMS & No IMS & IMS \\
\hline $\begin{array}{l}\text { NAL- } \\
\text { SMAC }\end{array}$ & $\begin{array}{c}13 / 20 \\
(65)\end{array}$ & $\begin{array}{c}14 / 20 \\
(70)\end{array}$ & $\begin{array}{c}14 / 20 \\
(70)\end{array}$ & $\begin{array}{c}17 / 20 \\
(85)\end{array}$ & $\begin{array}{l}3 / 20 \\
(15)\end{array}$ & $\begin{array}{l}7 / 20 \\
(35)\end{array}$ & $\begin{array}{c}30 / 60 \\
(50)\end{array}$ & $\begin{array}{c}38 / 60 \\
(64)\end{array}$ & & \\
\hline CT-SMAC & $\begin{array}{c}12 / 20 \\
(60)\end{array}$ & $\begin{array}{c}14 / 20 \\
(70)\end{array}$ & $\begin{array}{c}15 / 20 \\
(75)\end{array}$ & $\begin{array}{c}16 / 20 \\
(80)\end{array}$ & $\begin{array}{l}4 / 20 \\
(20)\end{array}$ & $\begin{array}{l}7 / 20 \\
(35)\end{array}$ & $\begin{array}{c}31 / 60 \\
(52)\end{array}$ & $\begin{array}{c}37 / 60 \\
(62)\end{array}$ & $1.0000^{\mathrm{b}}$ & $1.0000^{\mathrm{c}}$ \\
\hline SMAC & $\begin{array}{c}10 / 20 \\
(50)\end{array}$ & $\begin{array}{c}13 / 20 \\
(65)\end{array}$ & $\begin{array}{c}12 / 20 \\
(60)\end{array}$ & $\begin{array}{c}14 / 20 \\
(70)\end{array}$ & $\begin{array}{l}2 / 20 \\
(10)\end{array}$ & $\begin{array}{l}4 / 20 \\
(20)\end{array}$ & $\begin{array}{c}24 / 60 \\
(40)\end{array}$ & $\begin{array}{c}31 / 60 \\
(52)\end{array}$ & $0.3590^{\mathrm{d}}$ & $0.2678^{\mathrm{e}}$ \\
\hline
\end{tabular}

\footnotetext{
${ }^{a}$ Average of inoculum levels for three trials.
}

${ }^{\mathrm{b}-\mathrm{c}} p<0.05$ indicates a statistically significant difference between NAL-SMAC and CT-SMAC with and without IMS.

${ }^{\mathrm{d}-\mathrm{e}} p<0.05$ indicates a statistically significant difference between NAL-SMAC and SMAC with and without IMS. 
Table 2. Comparison of selective media and respective number of positive samples with and without IMS in radish sprouts

\begin{tabular}{|c|c|c|c|c|c|c|c|c|c|c|}
\hline \multicolumn{11}{|c|}{ Number of positive samples/Number of tested samples (\% positives) } \\
\hline Trials & \multicolumn{2}{|c|}{1} & \multicolumn{2}{|c|}{2} & \multicolumn{2}{|c|}{3} & \multicolumn{2}{|c|}{ Total } & \multirow{2}{*}{\multicolumn{2}{|c|}{$p$-value }} \\
\hline \multirow{2}{*}{$\begin{array}{c}\text { Inoculum } \\
\text { (CFU/500 g) }\end{array}$} & \multicolumn{2}{|c|}{1398} & \multicolumn{2}{|c|}{1408} & \multicolumn{2}{|c|}{1386} & \multicolumn{2}{|c|}{$1397^{\mathrm{a}}$} & & \\
\hline & No IMS & IMS & No IMS & IMS & No IMS & IMS & No IMS & IMS & No IMS & IMS \\
\hline $\begin{array}{l}\text { NAL- } \\
\text { SMAC }\end{array}$ & $\begin{array}{l}7 / 20 \\
(35)\end{array}$ & $\begin{array}{l}9 / 20 \\
(45)\end{array}$ & $\begin{array}{l}6 / 20 \\
(30)\end{array}$ & $\begin{array}{l}9 / 20 \\
(45)\end{array}$ & $\begin{array}{l}6 / 20 \\
(30)\end{array}$ & $\begin{array}{c}12 / 20 \\
(60)\end{array}$ & $\begin{array}{c}19 / 60 \\
(32)\end{array}$ & $\begin{array}{c}30 / 60 \\
(50)\end{array}$ & & \\
\hline CT-SMAC & $\begin{array}{l}6 / 20 \\
(30)\end{array}$ & $\begin{array}{c}10 / 20 \\
(50)\end{array}$ & $\begin{array}{l}5 / 20 \\
(25)\end{array}$ & $\begin{array}{l}7 / 20 \\
(35)\end{array}$ & $\begin{array}{l}5 / 20 \\
(25)\end{array}$ & $\begin{array}{l}9 / 20 \\
(45)\end{array}$ & $\begin{array}{l}6 / 60 \\
(27)\end{array}$ & $\begin{array}{c}26 / 60 \\
(44)\end{array}$ & $0.6883^{\mathrm{b}}$ & $0.5832^{\mathrm{c}}$ \\
\hline SMAC & $\begin{array}{l}3 / 20 \\
(15)\end{array}$ & $\begin{array}{l}7 / 20 \\
(35)\end{array}$ & $\begin{array}{l}2 / 20 \\
(10)\end{array}$ & $\begin{array}{l}6 / 20 \\
(30)\end{array}$ & $\begin{array}{l}4 / 20 \\
(20)\end{array}$ & $\begin{array}{l}6 / 20 \\
(30)\end{array}$ & $\begin{array}{l}9 / 60 \\
(15)\end{array}$ & $\begin{array}{c}19 / 60 \\
(32)\end{array}$ & $0.0509^{\mathrm{d}}$ & $0.0628^{\mathrm{e}}$ \\
\hline
\end{tabular}

${ }^{a}$ Average of inoculum levels for three trials.

${ }^{\mathrm{b}-\mathrm{c}} p<0.05$ indicates a statistically significant difference between NAL-SMAC and CT-SMAC with and without IMS.

${ }^{\mathrm{d}-\mathrm{e}} p<0.05$ indicates a statistically significant difference between NAL-SMAC and SMAC with and without IMS.

combination with IMS by comparing them to NALSMAC as a gold standard. The mean total aerobic count of the non-inoculated radish sprouts used in the three trials was approximately $5.0 \times 10^{7} \mathrm{CFU} / \mathrm{g}$. The inoculum levels needed to generate partial positives in each trial were $1,398,1,408$, and $1,386 \mathrm{CFU} / 500 \mathrm{~g}$ of radish sprouts, respectively. The number and percentage of positive samples out of 20 radish sprout samples in each combination of selective media with or without IMS are shown in Table 2. The mean recovery rate of the three trials with NAL-SMAC, CT-SMAC, and SMAC improved from $32 \%$ to $50 \%(+18 \%), 27 \%$ to $44 \%(+17 \%)$ and $15 \%$ to $32 \%(+17 \%)$, respectively, when IMS was combined with each of the selective media (Table 2). When compared to NAL-SMAC, the recovery rate of CT-SMAC decreased by $5 \%$ without IMS and by $6 \%$ with IMS, while reduced recovery rates, $17 \%$ less without IMS and $18 \%$ less with IMS, were also observed with SMAC (Table 2). Although there was no statistically significant difference in the number of positive samples with or without IMS, more samples were detected as positive when IMS was combined with all of the media used and the degree of the improvement was more significant in radish sprouts than in ground beef (Tables 1 and 2).

\section{Discussion}

Champman et al. (1994) reported that cefixime and tellulite, when added to SMAC, successfully reduced the growth of non-E. coli $\mathrm{O} 157$ background flora present in enrichment cultures. However, Karch et al. (1996) found that direct culture on SMAC agar or CT-SMAC is the least sensitive method for the isolation of E. coli $\mathrm{O} 157$ strains from the stools of HUS patients, due to the low number of $\mathrm{O} 157$ organisms excreted by HUS patients in stools and the high level of background flora; since then, the detection rate has been greatly improved by the introduction of IMS. As in the previous studies, we found more colorless colonies representing E. coli $\mathrm{O} 157: \mathrm{H} 7$ on CT-SMAC than on SMAC in ground beef and radish sprouts, and it was easier to distinguish the colorless colonies from background flora on CT-SMAC. In the present study, SMAC gave significantly poorer target recovery in both ground beef and radish sprouts, while CT-SMAC showed good recovery of E. coli $\mathrm{O} 157$ in ground beef, but still poor performance in radish sprouts.

Significant improvements in the selectivity and sensitivity of E. coli $\mathrm{O} 157$ detection in human and bovine feces were observed when IMS was used, as reported in previous studies (Chapman et al., 1994). Although the theoretical detection limit of IMS is as low as a single organism, the type and amount of background flora in samples, the type of enrichment broths used, the type of sample matrices, the incubation temperature and the incubation time all impact the sensitivity of detection with IMS (Fu et al., 2005; Karch et al., 1996; LeJeune et al., 2006; Mortlock et al., 1994). LeJeune et al. (2006) demonstrated the poor sensitivity of both IMS and direct plating for detecting E. coli $\mathrm{O} 157$ at low concentrations, below $100 \mathrm{CFU} / \mathrm{g}$, in bovine feces. Similar results were obtained in our study, showing no positive samples in radish sprout samples spiked with less than $3 \mathrm{CFU} / \mathrm{g}$ using IMS and direct plating of $24 \mathrm{~h}$ enrichment broth. Ogden et al. (2001) reported that the food source did not have an effect on the performance of selective agar in the IMS procedure evaluated for the isolation of both naturally-occurring and artificially-inoculated E. coli $\mathrm{O} 157$ in ground beef, cheese, apple juice and pepperoni, but not 
fresh produce such as radish sprouts. Similarly, in our study, incorporating IMS with the selective agars clearly improved the detection of E. coli $\mathrm{O} 157$ in both samples. However, in radish sprouts, which have a higher level of background flora than ground beef, IMS combined with CT-SMAC still did not yield $100 \%$ positive samples compared to the gold standard, showing that different food matrices could impact the degree of improvement of selective agar methods. The findings from this study highlight the potential for false-negative results in samples with high levels of background flora such as fresh produce products and fecal materials, when tested with the combination of IMS and E. coli O157 selective agars. An additional selective enrichment stage to eliminate other competing microflora prior to the IMS procedure, followed by plating on CT-SMAC, would be necessary for complete detection of $E$. coli $\mathrm{O} 157$ in fresh vegetables and fecal material, which are major culprits of E. coli O157:H7 food-borne outbreaks. This conclusion is supported by the fact that higher inoculum levels were required to generate partial positives in radish sprout samples, implying that detection of E. coli $\mathrm{O} 157: \mathrm{H} 7$ in samples with high background flora is somewhat more difficult and that sometimes one could fail to detect the organism with the best currently available methods. It is strongly recommended that IMS be used when samples with high background flora are analyzed. Although the detection sensitivity can be significantly improved using the current IMS-CT-SMAC procedure, this study obviously showed that better detection methods should be available for a food matrix such as radish sprouts that has a high level of background bacteria.

\section{Acknowledgments}

This work was supported by a Korea Research Foundation Grant funded by the Korean Government (MOEHRD, Basic Research Promotion Fund, KRF-2006-331F00051) and the Brain Korea 21 (BK21) project.

\section{References}

1. Ackers, M. L., Mahon, B. E., Leahy, E., Goode, B., Damrow, T., Hayes, P. S., Bibb, W. F., Rice, D. H., Barrett, T. J., Hutwagner, L., Griffin, P. M., and Slutsker, L. (1998) An outbreak of Escherichia coli O157:H7 infections associated with leaf lettuce consumption. J. Infect. Dis. 177, 1588-1593.

2. Aminul Islam, M., Heuvelink, A. E., Talukder, K. A., and de Boer, E. (2006) Immunoconcentration of Shiga toxin-producing Escherichia coli $\mathrm{O} 157$ from animal faeces and raw meats by using Dynabeads anti-E. coli $\mathrm{O} 157$ and the VIDAS system. Int. J. Food Microbiol. 109, 151-156.

3. Besser, R. E., Lett, S. M., Weber, J. T., Doyle, M. P., Barrett, T. J., Wells, J. G., and Griffin, P. M. (1993) An outbreak of diarrhea and hemolytic uremic syndrome from Escherichia coli $\mathrm{O} 157: \mathrm{H} 7$ in fresh-pressed apple cider. JAMA 269, 22172220.

4. Cleary, T. G. (2004) The role of Shiga-toxin-producing Escherichia coli in hemorrhagic colitis and hemolytic uremic syndrome. Semin. Pediatr. Infect. Dis. 15, 260-265.

5. Cooley, M., Carychao, D., Crawford-Miksza, L., Jay, M. T., Myers, C., Rose, C., Keys, C., Farrar, J., and Mandrell, R. E. (2007) Incidence and tracking of Escherichia coli O157:H7 in a major produce production region in California. PLoS ONE. 2, e1159.

6. Chapman, P. A., Ellin, M., and Ashton, R. (2001) A comparison of immunomagnetic separation and culture, Reveal and VIP for the detection of E. coli $\mathrm{O} 157$ in enrichment cultures of naturally-contaminated raw beef, lamb and mixed meat products. Lett. Appl. Microbiol. 32, 171-175.

7. Chapman, P. A., Wright, D. J., and Siddons, C. A. (1994) A comparison of immunomagnetic separation and direct culture for the isolation of verocytotoxin-producing Escherichia coli $\mathrm{O} 157$ from bovine faeces. J. Med. Microbiol. 40, 424427.

8. de Boer, E. (1998) Update on media for isolation of Enterobacteriaceae from foods. Int. J. Food Microbiol. 45, 43-53.

9. Deisingh, A. K. and Thompson, M. (2004) Strategies for the detection of Escherichia coli O157:H7 in foods. J. Appl. Microbiol. 96, 419-429.

10. Fratamico, P. M. and Bagi, L. K. (2007) Comparison of methods for detection and isolation of cold- and freezestressed Escherichia coli 0157:H7 in raw ground beef. $J$. Food Prot. 70, 1663-1669.

11. Fu, Z., Rogelj, S., and Kieft, T. L. (2005) Rapid detection of Escherichia coli O157:H7 by immunomagnetic separation and real-time PCR. Int. J. Food Microbiol. 99, 47-57.

12. Fujisawa, T., Sata, S., Aikawa, K., Takahashi, T., Yamai, S., and Shimada, T. (2000) Modification of sorbitol MacConkey medium containing cefixime and tellurite for isolation of Escherichia coli $\mathrm{O} 157: \mathrm{H} 7$ from radish sprouts. Appl. Environ. Microbiol. 66, 3117-3118.

13. Griffin, P. M., Ostroff, S. M., Tauxe, R. V., Greene, K. D., Wells, J. G., Lewis, J. H., and Blake, P. A. (1988) Illnesses associated with Escherichia coli O157:H7 infections. A broad clinical spectrum. Ann. Intern. Med. 109, 705-712.

14. Harrison, J. A., Harrison, M. A., and Rose, R. A. (1998) Survival of Escherichia coli $\mathrm{O} 157: \mathrm{H} 7$ in ground beef jerky assessed on two plating media. J. Food Prot. 61, 11-13.

15. Ibekwe, A. M., Watt, P. M., Grieve, C. M., Sharma, V. K., and Lyons, S. R. (2002) Multiplex fluorogenic real-time PCR for detection and quantification of Escherichia coli O157:H7 in dairy wastewater wetlands. Appl. Environ. Microbiol. 68, 4853-4862.

16. Jo, S. H., Ha, J. H., Kim, K. S., Shim, Y. H., Kwon, K. S., Han, J. A., Hwang, I. G., Ha, S. D., and Oh, D. H. (2007) 
Evaluation of selective media for isolation of foodborne bacteria. J. Fd. Hyg. Safety 22, 388-394.

17. Karch, H., Janetzki-Mittmann, C., Aleksic, S., and Datz, M. (1996) Isolation of enterohemorrhagic Escherichia coli O157 strains from patients with hemolytic-uremic syndrome by using immunomagnetic separation, DNA-based methods, and direct culture. J. Clin. Microbiol. 34, 516-519.

18. LeJeune, J. T., Hancock, D. D., and Besser, T. E. (2006) Sensitivity of Escherichia coli $\mathrm{O} 157$ detection in bovine feces assessed by broth enrichment followed by immunomagnetic separation and direct plating methodologies. J. Clin. Microbiol. 44, 872-875.

19. Mortlock, S. (1994) Recovery of Escherichia coli 0157:H7 from mixed suspensions: evaluation and comparison of precoated immunomagnetic beads and direct plating. $\mathrm{Br} . \mathrm{J}$. Biomed. Sci. 51, 207-214.

20. O'Brien, S. B., Duffy, G., Daly, D., Sheridan, J. J., Blair, I. S., and McDowell, D. A. (2005) Detection and recovery rates achieved using direct plate and enrichment/immunomagnetic separation methods for Escherichia coli O157:H7 in minced beef and on bovine hide. Lett. Appl. Microbiol. 41, 88-93.

21. Ogden, I. D., Hepburn, N. F., and MacRae, M. (2001) The optimization of isolation media used in immunomagnetic separation methods for the detection of Escherichia coli O157 in foods. J. Appl. Microbiol. 91, 373-379.
22. Onoue, Y., Konuma, H., Nakagawa, H., Hara-Kudo, Y., Fujita, T., and Kumagai, S. (1999) Collaborative evaluation of detection methods for Escherichia coli $0157: \mathrm{H} 7$ from radish sprouts and ground beef. Int. J. Food Microbiol. 46, 27-36.

23. Rangel, J. M., Sparling, P. H., Crowe, C., Griffin, P. M., and Swerdlow, D. L. (2005) Epidemiology of Escherichia coli O157:H7 outbreaks, United States, 1982-2002. Emerg. Infect. Dis. 11, 603-609.

24. Riley, L. W., Remis, R. S., Helgerson, S. D., McGee, H. B., Wells, J. G., Davis, B. R., Hebert, R. J., Olcott, E. S., Johnson, L. M., Hargrett, N. T., Blake, P. A., and Cohen, M. L. (1983) Hemorrhagic colitis associated with a rare Escherichia coli serotype. N. Engl. J. Med. 308, 681-685.

25. Tarr, P. I., Gordon, C. A., and Chandler, W. L. (2005) Shigatoxin-producing Escherichia coli and haemolytic uraemic syndrome. Lancet 365, 1073-1086.

26. Vernozy-Rozand, C., Mazuy, C., Ray-Gueniot, S., BoutrandLoei, S., Meyrand, A., and Richard, Y. (1998) Evaluation of the VIDAS methodology for detection of Escherichia coli O157 in food samples. J. Food Prot. 61, 917-920.

27. Zadik, P. M., Chapman, P. A., and Siddons, C. A. (1993) Use of tellulite for the selection of verocytotoxigenic Escherichia coli O157. J. Med. Microbiol. 29, 155-158,

(Received 2009.10.7/Revised 2010.3.5/Accepted 2010.3.10) 